Pentecostais. Consumo. Midiatização. Telenovela. 


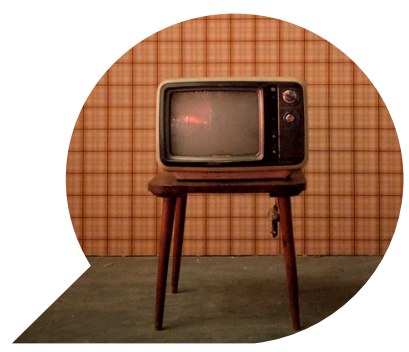

\title{
O consumo da telenovela pelos pentecostais: entre tensões e negociações
}

\author{
The consumption of soap opera by pentecostal religious: \\ between tensions and negotiations
}

El consumo de la telenovela por los pentecostales: entre tensiones y negociaciones

\begin{tabular}{c}
\hline RITA DE CÁSSIA ARAGÃO MATOS ${ }^{*}$ \\
\hline CATIANE ROCHA PASSOS DE SOUZA $^{* *}$ \\
\hline PRISCILA CHÉQUER \\
\hline CAIO BARBOSA NASCIMENTO \\
\hline
\end{tabular}

Resumo: Este artigo tem como objetivo principal discutir as tensões e negociações presentes no processo de reconhecimento da telenovela entre os fiéis das Igrejas Assembléias de Deus. Gênero televisivo comumente "demonizado" pelos fiéis desta denominação, as telenovelas frequentemente aparecem como tema nos discursos desses religiosos, fazendo surgir o interesse sobre a temática. $\mathrm{O}$ corpus de análise se origina de entrevistas com fiéis das Assembleias de Deus, membros de duas famílias residentes em

\footnotetext{
*Doutora, Universidade Federal da Bahia (UFBA) - rivalta@uol.com.br

** Doutoranda, Universidade Federal da Bahia (UFBA) - catirochapassos@gmail.com

*** Doutoranda, Universidade Federal da Bahia (UFBA) - priscilachequer@gmail.com

**** Mestrando, Universidade Federal da Bahia (UFBA) - caiobn.j@gmail.com
} 
Salvador - Bahia. Para a coleta de dados utilizamos o instrumento metodológico Histórias de Família. Para análise tomamos como fundamentação teórica os postulados de Eliseo Verón e Fausto Neto sobre o fenômeno Midiatização e sobre o conceito de Circulação discursiva.

Palavras-chave: Assembléia de Deus; Circulação; Midiatização; Religião; Telenovela.

\begin{abstract}
This article has as main objective to discuss the tensions and negotiations present in the process of recognition of the soap opera among the religious of the "Assembleias de Deus" churches. This television genre commonly "demonized" by the religious of this denomination, soap opera often appear as a theme in the discourses of these religious people, raising interest on the subject. The corpus of analysis originates from interviews with faithful of the "Assembleias de Deus" churches, members of two families that live in Salvador Bahia, to collect data we use the methodological tool Histórias de Familia. For analysis we take as theoretical foundation the postulates of Eliseo Verón and Fausto Neto on the phenomenon Midiatization and on the concept of discursive Circulation.
\end{abstract}

Key-words: Assembléia de Deus; Circulation; Midiatization; Religion; Soap Opera.

Resumen: Este artículo tiene como objetivo principal discutir las tensiones y negociaciones presentes en el proceso de reconocimiento de la telenovela entre los fieles de las Iglesias Asambleas de Dios. El género televisivo comúnmente "demonizado" por los fieles de esta denominación, las telenovelas a menudo aparecen como tema en los discursos de estos religiosos, haciendo surgir el interés sobre la temática. El corpus de análisis se origina de entrevistas con fieles de las Asambleas de Dios, miembros de dos familias residentes en Salvador - Bahia, para la recolección de datos utilizamos el instrumento metodológico Historias de Familia. Para el análisis tomamos como fundamentación teórica los postulados de Eliseo Verón y Fausto Neto sobre el fenómeno Midiatización y sobre el concepto de Circulación discursiva.

Palabras clave: Asamblea de Dios; Cirulación; Midiatización; Religión, Telenovela. 


\section{Introdução}

Dos anos 50 aos 90 as igrejas Assembleias de Deus (ADs) no Brasil defenderam a proibição à televisão. A normativa sobre a não utilização desse dispositivo comunicativo consta nas atas da Instituição. Dos anos 90 em diante essa normativa vem sendo flexibilizada a partir de uma relação mais estreita com os meios de comunicação. Antes demonizada, a televisão passa a ser considerada como um instrumento de evangelização. A "autorização" do consumo da televisão colocou o fiel assembleiano em contato com diversos conteúdos midiáticos intensificando o debate, sobretudo, sobre as telenovelas, consideradas como o programa mais emblemático dessa proibição.

A partir de 2015, com a emergência das telenovelas bíblicas ${ }^{1}$ produzidas pela Rede Record, novas leituras e gramáticas de reconhecimento vêm sendo observadas. Essa relação é o objeto de interesse do presente artigo, que busca, a partir do discurso de fiéis da Assembleia de Deus, discutir o processo de consumo das telenovelas brasileiras por esse grupo religioso. Considerando que o hábito de assistir TV integra o contexto familiar, escolhemos coletar narrativas de indivíduos pertencentes a núcleos familiares. Pina-Cabral e Pedroso (2005, p. 359) salientam que o método histórias de família é "extraordinariamente útil”, pois, analisadas em conjunto, essas histórias revelam modos de relacionamento e de interpretação do mundo em um contexto social e histórico.

Na intenção de observar um grupo diverso e considerando a ocupação territorial das ADs em Salvador, foram entrevistadas as famílias Gomes e Souza residentes em bairros distintos, respectivamente, Cidade Nova e Castelo Branco. A família Gomes e Souza (doravante representadas pelas letras $\mathrm{G}$ e S) são típicas famílias assembleianas, constituídas de pai e mãe, sendo o pai o principal provedor financeiro do lar e a mãe a principal responsável pela criação/educação dos filhos. Na família $G$, todos os membros são ativos das ADs. Foram entrevistados a mãe (G1), o filho (G2) e a nora (G3). G1 tem 56 anos, estudou até o $5^{\circ}$ ano do Ensino Fundamental (antiga $4^{\text {a }}$ série), é dona de casa, frequenta a AD há 45 anos. O casal G tem três filhos, duas filhas são missionárias em Goiânia,

\footnotetext{
${ }^{1}$ De acordo com Kanyat e Novaes (2016), o termo "telenovela bíblica" pode ser considerada uma expressão de apelo mercadológico utilizada pela Rede Record para diferenciar suas produções da concorrência (em especial da Rede Globo) e demarcar um nicho de mercado. Porém, os autores afirmam que esse termo não corresponde a uma classificação do gênero telenovela que é dividida apenas em três nomenclaturas: presentes, históricas e de época. Ainda segundo os autores, as produções da Record devem ser classificadas como telenovelas históricas.
} 
o filho de 23 anos (G2) cursa o $2^{\circ}$ ano do Ensino Médio, trabalha num mercadinho do bairro, é casado com G3 com quem convive há 6 anos e tem uma filha de 4 anos, moram com os pais G. G3 tem 22 anos, cursa o $3^{\circ}$ ano do Ensino Médio, é auxiliar administrativa em uma empresa de recursos humanos.

$\mathrm{Na}$ família S, dois filhos estão afastados da igreja. Nessa família, foram entrevistados a filha (S3), o pai (S1) e a mãe (S2). S1 tem 54 anos, completou o Ensino Médio, é motorista de carga pesada, frequenta as ADs há 33 anos. S2 é dona de casa, estudou até o $6^{\circ}$ ano do Ensino Fundamental (antiga 5a série), há 33 anos frequenta as ADs. S3 tem 29 anos, Ensino Médio completo, cursa o segundo ano no Bacharelado de Teologia, tem uma filha de 7 anos, é viúva e voltou a morar com os pais desde o falecimento do esposo.

As famílias foram selecionadas por indicação de frequentadores das ADs dos bairros, com referência quanto à permanência e frequência nas igrejas, bem como quanto ao hábito de assistir TV, pois há fiéis que não desenvolveram esse hábito. $\mathrm{O}$ procedimento de coleta ${ }^{2}$ foi a técnica de entrevistas semiestruturadas, ou seja, fizemos um roteiro como ponto de partida para a conversa. O roteiro das entrevistas começa com a identificação pessoal e familiar, seguida por questões sobre a prática religiosa que inclui perguntas sobre costumes. No caso dos assembleianos, falar de costumes engloba a mídia, sobretudo, a TV. Apesar de fazer parte de núcleo familiar e de possuir elementos comuns, como a religiosidade, cada colaborador foi entrevistado como "unidade de análise" (FAUSTO NETO, 2008, p. 100).

Nosso trabalho trata de um estudo da circulação. Desse modo, os recortes formam um texto resultado de outra temporalidade distinta daquela em que se deram os contatos com as telenovelas, ou melhor, da "emergência de um outro texto e que certamente não se trata daquele que se originou no encontro que eles (os receptores) estabeleceram com as emissões. Deles separados por dias ou meses" (FAUSTO NETO, 2008, p. 98). As condições de produção do discurso na circulação podem ser pensadas em sentido amplo e em sentido estrito. Em sentido amplo, temos a carga sócio-histórico-ideológica do discurso religioso em tensão ou não com a carga sócio-histórico-ideológica da telenovela. Em sentido estrito, temos a formulação dos dizeres na entrevista como

\footnotetext{
${ }^{2}$ As entrevistas são parte do corpus da pesquisa de doutorado em andamento "O que é lícito e o que convém? Efeitos de sentido da midiatização na religiosidade pentecostal brasileira" desenvolvida por Catiane Rocha P. de Souza no Programa Multidisciplinar em Cultura e Sociedade no IHAC- UFBA.
} 
"zona de contato" na qual detectamos a circulação dos efeitos de sentido do consumo da telenovela. Fausto Neto (2008) atenta para as várias defasagens na realização dessa atividade discursiva e afirma que "é no âmbito deste território, o da circulação - marcado por indeterminações e por dinâmicas complexas - que são gerados sentidos não sabidos, previamente" (FAUSTO NETO, 2008, p. 99).

\section{Os processos de reconhecimento e a circulação discursiva}

Lelo e Grohmann (2014) identificam três vertentes ${ }^{3}$ de estudos sobre o conceito de circulação que nos últimos anos têm sido retomadas por pesquisas desenvolvidas na área da Comunicação no Brasil. De acordo com os autores, é possível observar que o conceito de circulação assume características específicas a partir do escopo teórico onde está ancorado. Neste artigo, nos embasaremos nos estudos latino-americanos sobre o conceito, articulando as ideias de Antônio Fausto Neto (2010a; 2010b; 2011; 2012) e as noções desenvolvidas por Eliséo Verón (2005; 2013).

Verón desenvolve seu conceito de circulação a partir da noção de um intenso desequilíbrio no processo de comunicação. $\mathrm{O}$ esquema comunicacional não é entendido pelo autor como uma simples ação de transferência de sentidos onde as intenções são efetivadas automaticamente. Ao contrário, todos os níveis de comunicação, desde a interação face-a-face, sofrem com indeterminações, complexidades e uma intensa assimetria entre produção e recepção (que o autor chama de reconhecimento). Para Verón (2005), o sistema de produção de sentidos é composto por dois polos que correspondem à Produção e ao Reconhecimento. $\mathrm{O}$ pesquisador que se proponha a investigar esse sistema deverá se ocupar em entender: 1 . as condições/gramáticas em que foram produzidos determinados discursos; 2 . as condições/gramáticas que forneceram os modelos de leitura para o reconhecimento das formações discursivas.

Uma gramática de produção ou de reconhecimento tem a forma de um conjunto complexo de regras, que descrevem operações. Tais operações são aquelas que permitem definir ora as condições de produção, ora os resultados (numa outra produção discursiva) de uma determinada leitura (VERÓN, 2005, p. 51).

\footnotetext{
${ }^{3} 0$ conceito de circulação se desenvolve a partir da noção de discurso circulante nos estudos do francês Patrick Charaudeau filiado à nova análise do discurso francesa; 2. nos estudos britânicos a partir dos anos 90 sendo Roger Silverstone, Elizabeth Bird e Nick Couldry seus principais estudiosos; 3. no Brasil a partir dos trabalhos de Antônio Fausto Neto, por um viés sociossemiótico herdado do argentino Eliséo Verón, e de José Luiz Braga em uma perspectiva construcionista (LELO E GROHMAN, 2014).
} 
Verón (2013) afirma que os discursos se constituem pelas condições de produção, mas, sobretudo, pelas diversas individualidades (reconhecimento) dos membros de uma coletividade. Desse encontro surgem as rupturas/defasagens porque produção e reconhecimento se ancoram em diferentes condições discursivas. Para o autor, o nível da produção se associa com um dispositivo socioinstitucional e o nível do reconhecimento com um coletivo de atores. As Gramáticas de Reconhecimento se relacionam com o resultado dos efeitos do discurso, as possíveis leituras que podem ser realizadas. Nesse sentido, as gramáticas de reconhecimento são plurais, pois, uma condição de produção específica pode gerar mais de um efeito/leitura. Por estarem ancoradas em dimensões fundamentais como a estrutura social, econômica, política, religiosa, institucional, por exemplo, as gramáticas de reconhecimento são afetadas por dimensões no nível ideológico.

As postulações sobre produção e reconhecimento como pólos do sistema de produção de sentidos é o ponto de partida para compreender o conceito de circulação ${ }^{4}$ na obra de Verón. Para o autor, a circulação é o elo intermediário desse sistema que "se define como a defasagem, num dado momento, entre as condições de produção do discurso e a leitura feita na recepção" (VERÓN, 2005, p. 53). Assim, a circulação se apresenta como um fluxo que proporciona ao analista a possibilidade de entender as "relações-defasagens" entre produção e reconhecimento de um determinado discurso.

[Verón] Acentua a importância do desequilíbrio (defasagem) entre $\mathrm{P} / \mathrm{R}$, como diferença da relação destes dois polos. Esta seria constitutiva de um modelo de circulação, no qual os signos são transformados em sentidos, ao passar por um trabalho de dois circuitos produtivos (P/R) que operam segundo lógicas e condições distintas, cujos efeitos não seriam conhecidos previamente e nem se efetivariam, unilateralmente (FAUSTO NETO, 2016, p. 64).

O conceito de circulação proposto por Verón nos ajuda a pensar como se estabelecem as defasagens entre uma produção midiática e um coletivo de atores (potenciais consumidores). Nesse sentido, as condições de produção e reconhecimento nos apresentam pistas para compreender as diferentes leituras que a audiência efetua sobre um produto específico. Para Verón (2005), é possível pensar essa relação a partir da

\footnotetext{
${ }^{4}$ Em La Semiosis Social 2, Verón (2013, p. 293) apresenta um esquema gráfico para representar a circulação discursiva.
} 
proposta de circulação, como ele afirma: “[...] pode-se estudar as relações-defasagens entre as condições de produção do discurso audiovisual da televisão e as gramáticas de leitura na recepção, num determinado contexto social” (p. 53). No caso específico deste artigo, busca-se compreender as dinâmicas de reconhecimento (da telenovela) que estão ancoradas em uma dimensão social específica (a religião), investigando como se materializam essas defasagens, quais os rastros observáveis e como ela se torna material empírico para a pesquisa através dos discursos coletados nas entrevistas realizadas.

Fausto Neto $(2010 a, 2010 b)$ considera que o conceito de circulação lança luz para o entendimento da complexa relação entre produção e recepção $(\mathrm{P} / \mathrm{R})$ pensando esse espaço para além de uma “zona automática de passagem" de conteúdo. Ao propor uma outra abordagem para a relação $\mathrm{P} / \mathrm{R}$, o conceito de circulação complexifica os papéis dos agentes envolvidos nos processos de produção e reconhecimento e nos auxilia a repensar esse intervalo como uma zona de contato e produção discursiva onde emergem diálogos, indeterminações, rupturas e tensões. Para o autor, ao pensar o fluxo comunicacional a partir da ideia de circulação é possível estabelecer um deslocamento da problemática da produção para a do reconhecimento onde a circulação e suas defasagens se revelam. Nessa mesma perspectiva Verón (2005) afirma ser preciso superar a tendência das pesquisas cujo objetivo são apenas as estratégias discursivas no âmbito produtivo, pois, o conceito de circulação nos estimula a pensar nos dois polos da produção de sentidos:

o analista de discursos pode interessar-se ora pelas condições de produção de um discurso, ora pelas leituras que tiveram como objetivo tal discurso [...] Dizemos que ele se interessa, no primeiro caso, pela gramática de produção e, no segundo, por uma (ou várias) gramáti$\mathrm{ca}(\mathrm{s})$ de reconhecimento. É claro que pode interessar-se pelas duas, ou seja, interessar-se, na verdade, por um processo de circulação (VERÓN, 2005, p. 51).

Ao considerar que o processo de circulação se interessa pelos dois polos da produção de sentidos, Verón fornece a Fausto Neto as pistas para considerar a circulação como uma zona de contato, onde produção e recepção se encontram. Nessa zona de contato, sentidos são negociados a partir do que o autor chama de "jogos complexos de oferta e reconhecimento" (FAUSTO NETO, 2010a, p. 63). Os discursos ofertados são apreendidos pelas diversas gramáticas de reco- 
nhecimento a partir das quais novos sentidos são produzidos, nesse processo colocam-se em evidência as especificidades do discurso ofertado e as diversas estratégias de apropriação do público ancoradas em condições de reconhecimento específicas. Nessa articulação, segundo Verón (2005), "uma gramática de reconhecimento só pode 'materializar-se’ sob a forma de uma produção de sentido" (p. 60). Ou seja, para compreender o processo de circulação é necessário ter em mente que ambos os polos da comunicação produzem sentidos que são materializados através de discursos. É preciso buscar a materialidade dos sentidos do processo de reconhecimento, a que se tem o acesso, em parte, pelos novos discursos produzidos.

\section{Memória discursiva: os dizeres nas/das ADs sobre telenovela}

O modelo moderno ${ }^{5}$ da telenovela brasileira tem como característica a assimilação de elementos da cultura popular e a incorporação de temáticas em sintonia com assuntos que emergem de uma sociedade em constante mutação. A tônica realista das produções e sua aproximação com a sociedade brasileira torna a fronteira entre realidade e ficção uma linha tênue onde o evangélico vê refletidos os elementos da cultura secular que tanto busca combater. Ao incorporar em suas narrativas questões como homossexualidade, prostituição, traições conjugais, liberação sexual feminina, entre outros assuntos, a telenovela assume seu caráter profano que se opõe ao modelo de vida cristã. Dessa forma, os pentecostais identificam esse produto televisivo como uma importante arma para a disseminação de valores "mundanos". A Rede Globo, como maior produtora de telenovelas do país, consequentemente, figura nos sentidos desses religiosos como disseminadora de valores imorais e que deturpam a família.

Os membros da família Gomes afirmam que não assistem a nenhum programa transmitido pela emissora. Esse comportamento se estende inclusive para os familiares não participantes da pesquisa: "A gente só assiste no canal do SBT, a gente não assiste outro canal não. Canal 4. $\operatorname{SBT}$ (G3); "É porque lá a gente só assiste o 4 ou o 5" (G2); "No 11 eu não assisto nada" (G1). A opção familiar de não assistir a Rede Globo

\footnotetext{
${ }^{5}$ Martín-Barbero identifica as produções brasileiras como telenovelas modernas em contraposição às tradicionais produzidas em países como México e Colômbia. Como afirma o autor sobre o modelo moderno: "é que é aquele que, sem romper de todo o esquema melodramático, irá incorporar um realismo que possibilita a 'cotidianização da narrativa' e o encontro do gênero com a história e com algumas matrizes culturais do Brasil." (MARTÍN-BARBERO, 2004, p. 120)
} 
aparece nas entrevistas desse núcleo com justificativas de que tudo na emissora, principalmente as novelas, apelam à nudez e fazem apologia à homossexualidade. Os conteúdos das novelas globais são apontados como principais causas de a família não assistir à emissora:

(G1): Eu gosto de assistir novela, mas só gosto de novela do 4 [SBT], eu gosto da novela do 4 que é coisa mais simples, no 11 eu não assisto nada.

(G3): Depende do que se vê, porque tem novela, principalmente a do canal 11 né, que são coisas assim que você assiste, mas que você fica até com nojo de assistir porque é muita nudez, eles tão fazendo muita apologia principalmente com relação ao homossexualismo [...] eles botam pra poder as crianças, nossas crianças, filhos adolescentes entenderem que não tem erro nisso, mas o problema é, tem, e eles querem que a gente aceite isso, é complicado.

Essa cultura de hostilidade em relação à Rede Globo é construída pelos fiéis pentecostais partindo da perspectiva de que a emissora promove, sobretudo através das telenovelas, a desconstrução dos valores morais cristãos no Brasil. O controle da sexualidade e os valores familiares tradicionais são temáticas caras ao movimento pentecostal e, por isso, provocam tensões quando abordadas nas telenovelas de forma progressista. Ainda hoje, a sexualidade continua sendo um tabu e as novas configurações de casais "ameaçam" a família tradicional. Cunha (2004) assinala que as bases do puritanismo estadunidense que se assentaram no Brasil firmaram uma intensa repressão ao corpo e aos prazeres oriundos dele: "a teologia que fundamentava tal repressão indicava que o corpo deve ser resguardado, pois é ‘templo do espírito"' (p. 206). Dessa orientação emergem as regulações no que diz respeito principalmente à sexualidade e ao corpo feminino.

A prática da sexualidade fora do casamento, ou sem fins de reprodução, naturalizada nas telenovelas acirra a guerra contra o pecado e contra os pecadores. Na lógica cristã a Santidade Divina não coaduna com práticas ilícitas. Dessa forma, o desprezo do evangélico com relação ao pecado (e, conseqüentemente, ao pecador) são fomentados por características que foram herdadas do protestantismo histórico e que são conservadas na atualidade: uma acentuada busca pela "perfeição"; a identificação dos prazeres da "carne" como um repúdio a Deus; e uma busca incessante em triunfar sobre o pecado. O contato com o pecado, mesmo através da televisão, pode significar uma concordância, além de expor o fiel a tentações que colocam em risco a sua fé. 
Isso fica mais claro quando comparamos o modo como os entrevistados avaliam e diferenciam as novelas globais e as novelas da Rede Record. Para a maior parte dos membros das famílias entrevistadas, o problema não é o gênero telenovela em si, mas quais valores são sustentados nos conteúdos veiculados nesses produtos. Um dos entrevistados (S1) elabora uma diferenciação entre "mentira" e "ficção" para dar conta, dentro de uma esfera conceitual, da diferença entre as telenovelas baseada em fatos que, para ele, foram reais e tornamse ficcionalizados nas novelas bíblicas da Record; e outros produtos de caráter inédito e que teriam finalidades ideológicas ou políticas: as novelas seculares da Rede Globo.

Quando a telenovela aborda e defende o pensamento cristão e bíblico, como as telenovelas da Record citadas pelos entrevistados, o gênero se apresenta como uma obra de ficção baseada na "realidade". Isso porque a narrativa é construída com base no texto bíblico a partir de uma interpretação teológica ligada às igrejas de matriz evangélica. Além da temática, a não apologia a valores considerados imorais também contribui para que as telenovelas produzidas pela Record sejam mais aceitas. Já quando as novelas globais, que estão dentro de outras condições de produção, têm em sua narrativa cenas consideradas anticristãs ou conteúdos que, na visão dos assembleianos, defendem a inversão moral dos valores, nós estamos, segundo a entrevistada S2, diante de uma "mentira": "porque a gente sabe que era uma mentira que tava acontecendo na televisão, é uma novela, é uma mentira, são casos que às vezes até acontece na vida real, mas também tem muitos que é mentira”.

Bakker (2008) observa que os sentidos produzidos pelos telespectadores evangélicos, em geral, perpassam por uma crença de que narrativas que não tratem de assuntos ligados positivamente ao universo religioso, seria uma sedução do Mal para enlaçar os fiéis através de mentiras apresentadas como verdade. Nessa concepção, as telenovelas "na potência de suas imagens e estilos narrativos, ofereceriam poderosas seduções satânicas [à medida que] apresentam uma realidade falsa e sedutora que envolve seus espectadores numa diabólica mentira" (BAKKER, 2008, p. 06). A Rede Record, nesse sentido, é positivada por esses receptores evangélicos pentecostais, enquanto a Globo, secular, é alvo de críticas e, verdadeiramente, demonizada:

(S1): Eu não gostava de novela, mas tem uma novela aqui na Record agora que eu tou assistindo, Escrava Mãe e os 10 mandamentos que 
terminou e agora tem A terra Prometida, mesmo que tem alguma divergência, mas a gente sabe que ali é uma cena, é uma coisa, uma ficção, a palavra é essa, uma ficção.

A relação entre parte do público evangélico e a Rede Globo ganha contornos ainda mais tensos se levarmos em conta outras esferas de produção. Enquanto o público assembleiano por nós entrevistado, acusa a emissora da família Marinho de divulgar "mentiras" e de promover valores anticristãos através de sua narrativa telemidiática, o canal, por sua vez, retrata o público evangélico de forma estereotipada em suas produções e lhes dá espaço reduzido e marginal.

Isso, não apenas comparada às inúmeras produções dramatúrgicas calcadas na religiosidade católica tradicional (ex: A Padroeira, 20012002) como também nas religiões orientais, como o Budismo, o Islamismo ou Hinduísmo que recebem expressivo espaço, e de forma positiva, na teledramaturgia global. Além dos inúmeros exemplos de novelas que são inspiradas ou abordam aspectos da doutrina espírita, também uma minoria religiosa no Brasil, mas que alcança muito mais destaque nas produções globais que as igrejas evangélicas.

Esses elementos nos levam a inferir que os modos de produção existentes na Rede Globo contribuíram fortemente para determinar as estratégias e os padrões de consumo operados pelo público evangélico e, em certa medida, para instaurar uma cultura de hostilidade entre a maior emissora do país e essa parcela do público. Os religiosos assembleianos, apesar de reconhecerem a possibilidade do consumo da telenovela, não admitem o conteúdo produzido pela Rede Globo e encontram nas novelas da Rede Record a possibilidade de conjugar o gosto pelo formato, com a aceitação do conteúdo.

\section{Considerações não-finais: "Marinho e Macedo, os dois tão querendo dinheiro meu irmão"}

Nos dizeres dos entrevistados citados nesse artigo se apresentam tensões quanto ao reconhecimento da telenovela. Essas tensões dizem respeito às condições de reconhecimento dos indivíduos (fiéis das ADs) que se (des)identificam com as condições de produção das telenovelas. As telenovelas da Rede Record ou da Rede Globo, antes mesmo de sua exibição, são pré-concebidas no imaginário desses religiosos, pois se nutrem dos sentidos já pré-estabelecidos a essas emissoras. Apesar das 
tensões, em alguns dizeres, surgem traços de negociação quando reconhecem na Record elementos que aproximam a telenovela do universo cristão (os dizeres de S1, por exemplo). Esses traços dizem respeito ao fato da telenovela da Record adotar, nos últimos anos, conteúdo que se apropria de narrativas bíblicas, ou mesmo tem relação com o fato da Rede Record ser propriedade do Bispo Edir Macedo, líder da Igreja Universal do Reino de Deus. Esses traços se contrapõem, nesses dizeres aqui apresentados, à produção da Rede Globo, emissora que se apresenta na memória discursiva dos assembleianos como inimiga dos cristãos e, desse modo, do próprio Deus.

Apesar dos dizeres que ora tensionam o reconhecimento da telenovela, de modo geral, o fato dela ser exibida pela Record e trazer adaptações das narrativas aparecem como fatores que negociam esse tipo de produção nas condições de reconhecimento do fiel das Assembleias de Deus. Essa negociação traz a sensação de conforto espiritual, para o fiel que considerava pecado assistir telenovela (os dizeres de S2 destacam), ou seja, a problemática que caracterizava esse reconhecimento como pecado se desfaz. Essa negociação se amplia na medida em que, de algum modo, se acredita que assistindo a telenovela da Record está contribuindo para a divulgação da Bíblia ou até mesmo está ajudando a Record a derrubar o império da Rede Globo, como se o consumo da telenovela da Record inserisse o "telefiel" na luta do bem contra o mal.

Além do público evangélico, que inclui os assembleianos, o conteúdo bíblico das telenovelas da Record vem atraindo o público brasileiro, em geral. A razão desse sucesso tem relação com a própria formação cultural judaico-cristã que contribui para constituir os gostos e hábitos de consumo. Sobre esse aspecto, destaca S3: "Mas nem todo público que assiste também é cristão. É sim, nem todos que são evangélicos. Tem pessoas que não são de nenhuma religião e assistem”. O brasileiro se agrada desse tipo de produção, pois projeta uma materialidade discursiva que se enquadra nos princípios que formulam o "superego cultural" da nação ${ }^{6}$, quer dizer, é como se ao assistir telenovelas bíblicas aliviasse a culpa moral internalizada por se estar consumindo telenovela e televisão, ou a culpa por não mais ler as escrituras sagra-

\footnotetext{
${ }^{6}$ Em "O Mal estar na civilização" (1930) Freud trata do superego como instância que resulta da cultura de uma época e a relaciona ao imperativo cristão: "estamos particularmente interessados naquela que é provavelmente a mais recente das ordens culturais do superego, o mandamento de amar ao próximo como a si mesmo" (FREUD, [1930]1997, p. 108). Nesse sentido é que entendemos os princípios cristãos como a base empírica da formação do superego cultural brasileiro, pois nossa cultura fundamenta-se desses princípios independente das escolhas religiosas dos indivíduos.
} 
das, ou até a culpa por não mais ir às igrejas, onde essas narrativas são recontadas, enfim, esses tipos de telenovelas vêm agradando um grande número de cristãos "desigrejados".

Embora vislumbramos uma tendência à negociação desse tipo de produção (telenovela bíblica da Rede Record), até mesmo pelos assembleianos que são institucionalmente orientados a não assistir telenovela, os dizeres de S3 nos chamou a atenção por apresentar uma visão crítica quanto às produções bíblicas da Record. Vale destacar que S3 é praticante assídua da igreja, professora da Escola Bíblica Dominical e cursa Bacharelado em Teologia. Esses dados nos indicam que a visão da entrevistada pode ser uma reação também conservadora diante das inovações. S3 aponta aspectos que, segundo a entrevistada, aproximam e/ou até iguala as produções bíblicas da Record com as telenovelas da Rede Globo:

(S3): Só novela que não vejo né. Mesmo sendo uma novela cristã. Eu digo assim, eu não vejo diferença nenhuma entre essa (Os Dez Mandamentos) e a outra, assim a da Globo. É minha opinião, é o que eu falei, tipo assim, a diferença de Marinho e Edir Macedo, os dois tão querendo dinheiro, meu irmão! Então assim, as pessoas se enganam porque é uma história bíblica.

Apesar de, durante a entrevista, assumir que assiste televisão e dizer que não considera pecado esse comportamento, S3 declara que não vê telenovela, porque acredita que esse tipo de produção não contribui em nada para sua vida, nem mesmo as telenovelas que adaptam narrativas bíblicas. Diferente dos demais tipos de produção televisiva, S3 reconhece nas telenovelas um caráter mercadológico como fim primário. Esse caráter mercadológico que abarca a telenovela, independente do conteúdo, conforme os dizeres de S3, coloca as duas emissoras de televisão, Rede Globo e Rede Record, na mesma condição. Mais ainda, coloca o próprio Edir Macedo em analogia a Roberto Marinho, proprietário do Grupo Globo, que, embora falecido desde 2003, continua a personificar a imagem do dono da emissora. Em relação a Macedo, a imagem do empresário apaga a imagem do bispo, ou seja, desconstrói sua figura religiosa.

Por fim, em síntese, a questão da problemática que envolve o reconhecimento da telenovela da Record pelos fieis das Assembleias de Deus não diz respeito apenas ao seu conteúdo bíblico, ou mesmo à questão de se tratar de teleficção. Também não tem relação com a interpene- 
tração que se faz do discurso religioso com o discurso midiático fictício-televisivo transformando o sagrado em mercadoria. Esse tipo de transformação embora se apresente como novo nas telenovelas, não é novidade: narrativas bíblicas se fizeram presentes e sofreram adaptações por diversos tipos de produção, desde o teatro medieval ao cordel. A problemática está no domínio que se faz das lógicas de produção e circulação das telenovelas, ou seja, a transferência desse domínio da Globo para Record significa se apropriar da capacidade de produzir e se fazer circular o produto midiático mais consumido no país: a telenovela.

\section{REFERÊNCIAS}

BAKKER, A. W. A. A diabólica ficção: recepção televisiva em uma comunidade evangélica da Ilha Grande. Anais da $26^{\circ}$ Reunião Brasileira de Antropologia, Porto Seguro/BA, 2008. Disponível em: https://goo.gl/jGJHbi Acesso em: 10.02.2017

CUNHA, M. N. Vinho novo em odres velhos: um olhar comunicacional sobre a explosão gospel no cenário religioso evangélico no Brasil. 347 f. 2004. Tese (Doutorado) - Escola de Comunicação e Artes, USP - São Paulo, 2004.

FAUSTO NETO, A. Fragmentos de uma analítica da midiatização. Dossiê - Matrizes, n. 2, abril 2008. p. 89-105.

A. As bordas da circulação. Revista ALCEU, v. 10, n. 20, jan - jun, 2010a, p. $55-69$.

.A. Circulação além das bordas. In: FAUSTO NETO, A.;

VALDETTARO, S.(ORG.). Mediatización, Sociedad y Sentido: diálogos entre Brasil y Argentina. Universidad Nacional de Rosario, Rosário, 2010b, p. 02 - 17.

A. AD - Rumos de uma nova analítica. In: FERREIRA, G. M.;

SAMPAIO A. O. (ORG) Mídia, Discurso e Sentido. Salvador: EDUFBA, 2011. p. 27 42.

A. Circulação, o "ponto-cego" que se desvenda. Anais do I

Colóquio Semiótica das Mídias, v. 01, n. 01, João Pessoa, 2012.

A. O conceito de recepção na obra de Eliséo Verón: 1968 - 2013.

Revista Galáxia, n. 33, set-dez, 2016, p. 63 - 76. 
FREUD, Sigmund (1930). O mal-estar na civilização. Trad. José Octávio de Aguiar Abreu. Rio de Janeiro: Imago, 1997.

KANYAT, L; NOVAES, A. Telenovela bíblica: Ficção televisiva e cultura gospel brasileira. XI Conferência Brasileira de Comunicação Eclesical (Eclesiocom), Engenheiro Coelho, SP, 2016.

LELO, T. V.; GROHMANN, R. A diversidade do conceito de circulação nos em Comunicação. ECCOM, v. 5, n. 9, jan/jun, 2014.

MARTÍN-BARBERO, J. Os exercícios do ver: hegemonia audiovisual e ficção televisiva. 2 ed. São Paulo: Editora Senac São Paulo, 2004.

PINA-CABRAL, J.; PEDROSO de L. Como fazer uma história de família: um exercício de contextualização social. Etnográfica, v.9, n.2, p.355-388, 2005.

VERÓN, E. Fragmentos de um tecido. Ed. Unisinos: São Leopoldo, 2005.

, E. Midiatização, novos regimes de significação, novas práticas analíticas? In: FERREIRA, G. M.; SAMPAIO, A. O. (Org.) Mídia, discurso e sentido. Salvador: Edufba, 2011.p. 17 - 25

E. La Semiosis Social, 2: ideas, momentos, interpretantes. Ciudad Autónoma de Buenos Aires: Paidós, 2013.

E. Teoria da midiatização: uma perspectiva semioantropológica e algumas de suas consequências. Revista Matrizes, Jan - Jun, nº 01, Rio de Janeiro, 2014. p. 13-19. 